\title{
Contextos, políticas e resultados de avaliação no ensino médio: um estudo em quatro estados brasileiros
}

Sofia Lerche Vieira* Eloísa Maia Vidal** Willana Nogueira M. Galvão***

*(Universidade Estadual do Resumo: 0 estudo discute as políticas de avaliação de Ceará - Uece - Fortaleza, CE) larga escala nacionais e estaduais em quatro unidades da federação - São Paulo, Goiás, Pernambuco e Ceará **(Universidade Estadual do -, focalizando suas repercussões em escolas de ensino Ceará - Uece - Fortaleza, CE) médio com bons resultados, localizadas em territórios socioespaciais vulneráveis. A amostra envolveu 24 escolas ***(Universidade Estadual do Ceará e a metodologia adotou a perspectiva quanti-qualitativa de análise. 0 estudo da configuração dos sistemas nacionais e estaduais mostra a existência de mais semelhanças que diferenças entre uns e outros, o que levaria a indagar se não estaria havendo uma duplicação de esforços e recursos em nome da melhoria da qualidade da educação, gerando uma sobrecarga para as escolas e todos os envolvidos. Os depoimentos dos participantes evidenciam uma aguda consciência de que a cultura de avaliação chegou para ficar, e chama a atenção sobre alguns efeitos deletérios gerados pelos seus excessos.

Palavras-chave: Política educacional. Avaliação de larga escala. Ensino médio. Gestão escolar. 


\section{INTRODUÇÃO}

Este artigo discute políticas de avaliação de larga escala no país com base em dados da pesquisa "Políticas para o ensino médio: o caso de quatro estados", realizada em quatro estados brasileiros: Ceará, Pernambuco, São Paulo e Goiás. 0 estudo é feito numa perspectiva quanti-qualitativa de análise, procurando situar a avaliação no contexto mais geral da educação brasileira e dessas unidades federadas. A amostra consistiu de 24 escolas que ofertam ensino médio, localizadas em cidades desses estados e que se situam em regiões socioespacialmente vulneráveis, mas que conseguem apresentar bons resultados no desempenho dos estudantes nas avaliações de larga escala estadual.

Busca-se identificar as possíveis articulações entre as políticas nacionais e estaduais e as repercussões de tais iniciativas no âmbito escolar. Para tanto, recorre-se a informações obtidas mediante a aplicação de questionários e realização de entrevistas com diretores de escola, professores e alunos por meio de trabalho de campo durante o ano de 2015, bem como a alguns indicadores dos referidos estados, comparando-os entre si e tendo como referência as médias brasileiras.

A análise do tema justifica-se pela centralidade da avaliação no contexto das políticas educacionais brasileiras e dos referidos estados, conforme se constatou no percurso da pesquisa do qual este estudo se constitui um recorte. Importante destacar que, como em outros contextos, a avaliação tem sido a pedra angular das reformas educacionais em curso nas últimas décadas, configurando-se como tema estratégico na agenda da política educacional contemporânea. No Brasil, este debate, que remonta à década de 1990, vem conquistando espaço crescente, tanto do ponto de vida da formulação quando da implementação das políticas educacionais. Compreender o seu significado no âmbito da pesquisa da qual este trabalho faz parte requer um duplo movimento: de um lado, compreender o(s) contexto(s) em que a avaliação se situa; de outro, entender seus contornos nas políticas concebidas pela União e pelos Estados, de modo particular, São Paulo, Goiás, Pernambuco e Ceará. Nesse sentido, os tópicos que se seguem procuram situar: os contextos das políticas de avaliação, as políticas nacionais e estaduais de avaliação, alguns entrelaces entre políticas nacionais e estaduais, resultados de avaliação, repercussões na escola e, para finalizar, alguns de seus problemas, desafios e perspectivas. Comecemos pelos seus contextos. 
Como toda e qualquer política, a avaliação deve ser situada em um panorama mais amplo, em que devem ser examinados aspectos históricos, relativos a um contexto mundial, nacional e local. Assim, na dinâmica da avaliação enquanto política pública, há que se buscar os nexos entre fatores diversos, alguns dos quais aqui mencionados.

Vários autores têm destacado o caráter estratégico da avaliação no contexto das reformas contemporâneas que têm se realizado em países como o Canadá, a Austrália, o Reino Unido, os Estados Unidos e diversos outros territórios europeus (LEVIN, 2001; BARROSO, 2005; MAROY, 2011). Desses contextos vão ser originários importantes elementos das políticas de avaliação que aportaram no Brasil na esteira de tais influências dos anos 1990 em diante.

O protagonismo crescente das agências multilaterais é um elemento indutor das políticas de avaliação. Neste panorama, tem sido estratégico o papel de diversos organismos internacionais, dentre eles a Organização e Cooperação para o Desenvolvimento Econômico (OCDE). Um estudioso da matéria (TEODORO, 2012) defende a tese de que a emergência de sistemas estatísticos internacionais ${ }^{1}$ foi decisiva para o incremento das políticas que privilegiam a comparação, sem levar em conta as circunstâncias próprias dos diferentes contextos em que estas se materializam.

Em artigo sobre o sistema educacional, o português Afonso (2001) localiza as políticas de avaliação no contexto das mudanças no papel do Estadonação, que passa a não mais ser o único agente na formulação de políticas educacionais. Dentre os autores que assumem essa perspectiva, Barroso (2005) e Maroy (2011) apontam a centralidade da avaliação de resultados nas políticas forjadas no contexto pós-globalização. Há, portanto, um contexto mais amplo propício à avaliação, que se constrói em uma ambiência onde se combinam fatores diversos, tanto de ordem interna como externa.

O Pisa, sigla do Programme for International Student Assessment, que, em português, foi traduzido como Programa Internacional de Avaliação de Alunos, é um programa internacional de avaliação comparada aplicada a estudantes da 7 ạ série em diante, na faixa dos 15 anos, idade em que se pressupõe o término da escolaridade básica obrigatória na maioria dos países. Esse programa é desenvolvido e coordenado internacionalmente pela Organização para Cooperação e Desenvolvimento Econômico (OCDE), havendo em cada país participante uma coordenação nacional. No Brasil, o Pisa é coordenado pelo Instituto Nacional de Estudos e Pesquisas Educacionais Anísio Teixeira (Inep). 
Talvez seja possível afirmar que essa agenda chega ao Brasil um tanto tardiamente. Se examinarmos, por exemplo, o debate do início dos anos 1990, já sob a égide da Constituição de 1988, que tantas mudanças trouxe para o campo educacional, iremos verificar que o tema da avaliação é praticamente ausente. Ainda que houvesse vozes isoladas em defesa de políticas de avaliação, até então estas se configuravam como "demandas reprimidas", tema que, na definição de Rua (s. d.), poderia ser denominada como um "estado de coisas", ou seja, um problema que embora possa estar presente nas cogitações dos formuladores de políticas, ainda não merece uma solução enquanto política pública.

Se a avaliação era pouco tematizada no debate mais amplo do campo educacional, no âmbito das estruturas governamentais começa a ser objeto de algumas iniciativas. Não cabe aqui detalhar essa trajetória, que tem sido aprofundada pela literatura (GATTI, 2009; WERLE, 2010, 2011; FREITAS, 2003, e outros) e por suas especificidades requereria esforço de análise que ultrapassa a presente reflexão.

É oportuno lembrar que a Lei de Diretrizes e Bases da Educação Nacional (LDB, Lei no 9.394/96) inclui a avaliação entre as incumbências no sentido de "assegurar processo nacional de avaliação do rendimento escolar no ensino fundamental, médio e superior, em colaboração com os sistemas de ensino, objetivando a definição de prioridades e a melhoria da qualidade do ensino" (Art. $9^{\circ}, \mathrm{VI}$ ). Ora, esta não é uma escolha casual. Na verdade, o dispositivo da LDB que atribui ao governo federal a responsabilidade pela "coordenação da política nacional de educação (Art. $8^{\circ}$, $\S^{\circ}{ }^{\circ}$ ) se articula ao artigo antes citado que refere o “processo nacional de avaliação do rendimento escolar”. Esta definição ocorre em 1996, no governo Fernando Henrique Cardoso, já tendo sido criado o Sistema de Avaliação da Educação Básica (Saeb)² ${ }^{2}$ Embora ainda nascente enquanto sistema, vai ganhar protagonismo central na formulação e implementação das políticas governamentais que vão se configurar no campo a partir de então.

\section{PolítICAS PÚBLICAS SOBRE AVALIAÇÃO DE LARGA ESCALA}

Este tópico procura apresentar as políticas nacionais e estaduais de avaliação de larga escala, criadas no âmbito governamental para a educação básica. No

Ver: BRASIL. Ministério da Educação e do Desporto. Portaria no 1.795, de 27 de dezembro de 1994. Cria o Sistema Nacional de Avaliação da Educação Básica. Diário Oficial [da] República Federativa do Brasil, Brasília, DF, 28 dez. 1994. 
âmbito nacional, têm destaque o Saeb e o Exame Nacional do Ensino Médio (Enem), ambos criados na década de 1990, e o Índice de Desenvolvimento da Educação Básica (Ideb); no que se refere aos quatro estados pesquisados, são abordados os sistemas estaduais de avaliação, criados entre 1992 e 2011.

\subsection{Políticas nacionais}

No que tange às políticas educacionais de abrangência nacional, este tópico abordará o Saeb, o Enem e o Ideb, apresentando um breve descritivo de cada um deles de modo a mostrar seu protagonismo nos rumos da política educacional brasileira nos últimos anos.

\subsubsection{O Sistema de Avaliação da Educação Básica (Saeb)}

Criado no governo Itamar Franco, o Saeb teve sua primeira edição em 1990, aplicado em algumas séries de uma amostra de escolas públicas urbanas que ofertavam ensino fundamental, sendo os estudantes avaliados em língua portuguesa, matemática e ciências. Só a partir de 1995, o Saeb passa a adotar uma metodologia de construção e aplicação de testes que permite a comparação de resultados ao longo do tempo ${ }^{3}$. É nesse momento que, de fato, pode-se falar da criação de um sistema de avaliação de larga escala no país, que passa a ser utilizado de forma mais direta na formulação e implementação de políticas públicas.

De 1995 a 2003, o Saeb é aplicado de forma amostral, abrangendo, no entanto, todos os estados da federação e todas as redes de ensino, nas disciplinas língua portuguesa e matemática, e nas 4a e $8^{\underline{a}}$ séries do ensino fundamental e $3^{\mathfrak{a}}$ série do ensino médio. 0 seu caráter amostral, no entanto, criava dificuldades no reconhecimento dos resultados por parte dos sistemas de ensino e de suas respectivas escolas.

A falta de uma cultura de trabalho com indicadores quantitativos, especialmente no que diz respeito a medidas de desempenho escolar em avaliações dessa natureza, provocou um verdadeiro choque com a divulgação dos primeiros resultados do Saeb, que mostram uma situação alarmante, muito abaixo das expectativas de formuladores de políticas. Nesse período,

3 A Teoria de Resposta ao Item (TRI) faz a relação entre a habilidade do aluno e a probabilidade de que esse aluno responda corretamente um item da prova. Utiliza um conjunto de modelos matemáticos que relacionam um ou mais traços não observados de um indivíduo com a probabilidade de este dar certa resposta a um item. A TRI oferece a possibilidade de comparação dos resultados obtidos nos testes com outros aplicados para a mesma série e disciplina em anos anteriores e subsequentes, em avaliações similares. 
os resultados obtidos pelo sistema educacional brasileiro em seu conjunto apontavam quedas sucessivas, o que mobilizou estudiosos e analistas na busca de explicações que justificassem tal comportamento.

Em 2005 o Saeb é reestruturado, passando a ser composto por duas avaliações: Avaliação Nacional da Educação Básica (Aneb), de caráter amostral e Avaliação Nacional do Rendimento Escolar (Anresc), conhecida como Prova Brasil ${ }^{4}$, de caráter censitário para as escolas públicas. O intuito dessa mudança era subsidiar as demandas dos "gestores públicos, educadores, pesquisadores e da sociedade em geral por informações sobre o ensino oferecido em cada município e escola”.

Corroborando o fortalecimento das políticas de avaliação, as mudanças no Saeb apontam para o interesse em "auxiliar os governantes nas decisões e no direcionamento de recursos técnicos e financeiros, assim como a comunidade escolar, no estabelecimento de metas e na implantação de ações pedagógicas e administrativas, visando à melhoria da qualidade do ensino" ${ }^{\circ}$. 0 governo Luiz Inácio Lula da Silva (2003-2010) não apenas mantém a centralidade das políticas de avaliação, como também cria mecanismos para sua consolidação e aprimoramento. Assim, em 2005 é instituída avaliação de caráter censitário para as escolas públicas de ensino fundamental, viabilizando a comparabilidade entre resultados. Se antes era possível verificar apenas informações muito gerais de avanços e retrocessos em termos do país e dos estados, a ampliação do sistema de avaliação veio permitir que municípios e escolas tivessem seus resultados divulgados, o que, pelo menos em tese, permitiria que estes se "vissem" nos dados retratados.

\subsubsection{O Exame Nacional de Ensino Médio (Enem)}

O Enem, criado em 1998, tinha como objetivo inicial "avaliar o desempenho do estudante ao fim da educação básica, buscando contribuir para a melhoria da qualidade desse nível de escolaridade” (2005, p. 17) num contexto em que o ensino médio está em franco processo de expansão. Realizado anualmente pelo Inep, de caráter voluntário para alunos concluintes do ensino médio e, também, os egressos deste nível de ensino em qualquer de suas modalidades,

\footnotetext{
Mais recentemente, em 2013, o Saeb incorpora a Avaliação Nacional da Alfabetização (ANA), de natureza censitária dirigida aos alunos das escolas públicas cursando $3^{\circ}$ ano do ensino fundamental e que tem como objetivo principal avaliar os níveis de alfabetização e letramento em língua portuguesa, alfabetização, matemática e condições de oferta do ciclo de alfabetização das redes públicas.

〈http://portal.inep.gov.br/web/saeb/historico〉.

〈http://portal.inep.gov.br/web/saeb/historico〉.
} 
a concepção inicial era permitir a cada participante fazer uma autoavaliação para orientar melhor escolhas futuras, não só em relação à continuidade dos estudos, como também para o mercado de trabalho. Funcionava ainda como uma modalidade alternativa ou complementar aos exames de acesso aos cursos profissionalizantes pós-médio, ao ensino superior e aos processos de seleção nos diferentes setores do mercado de trabalho.

Pouco a pouco o Enem passa a ser adotado como instrumento de seleção para a educação superior. Em 2002, contou com a adesão de cerca de 1.300 .000 participantes e mais de 400 instituições de ensino superior o utilizaram como critério de acesso (INEP, 2002). A partir da criação do Programa Universidade para Todos (Prouni) ${ }^{7}$, os resultados do Enem passaram a ser usados como critério para a distribuição das bolsas de estudo. Assim, os estudantes que alcançassem as melhores notas no exame teriam maiores chances de escolher o curso e a instituição de ensino superior privada em que poderiam estudar.

Nos anos iniciais de sua aplicação, a adoção dos resultados do Enem como parte do processo seletivo para acesso aos cursos superiores teve maior adesão por parte das instituições de ensino superior privadas. A partir de 2010, o Ministério da Educação coloca o Enem na pauta de discussão como processo seletivo de admissão aos cursos de graduação nas instituições federais. Modificações são propostas ao modelo de prova do Enem e cria-se o Sistema de Seleção Unificada (Sisu). A grande maioria das Instituições de Ensino Superior Federais (Ifes) adere à proposta do novo Enem.

Simultaneamente às mudanças no Enem, o governo federal cria a lei de $\operatorname{cotas}^{8}$, que prevê a ocupação de $50 \%$ das vagas nas Ifes por egressos das escolas públicas e “autodeclarados pretos, pardos e indígenas, em proporção no mínimo igual à de pretos, pardos e indígenas na população da unidade da Federação onde está instalada a instituição, segundo o último censo do Instituto Brasileiro de Geografia e Estatística” (art. 3ํ)), num prazo máximo de quatro anos a partir da publicação da lei. Para as escolas públicas, o novo Enem também representa uma oportunidade de ampliar o acesso dos alunos

7 Somente poderá candidatar-se ao Prouni o estudante que tiver participado do Enem e obtido a nota mínima divulgada pelo Ministério da Educação. Não são consideradas as notas obtidas nos Enem anteriores. Sua inscrição é gratuita para alunos da rede pública de ensino.

8 A lei $n$ ํㅜ 12.711, de 29 de agosto de 2012, estabelece em seu artigo 10 que “As instituições federais de educação superior vinculadas ao Ministério da Educação reservarão, em cada concurso seletivo para ingresso nos cursos de graduação, por curso e turno, no mínimo 50\% (cinquenta por cento) de suas vagas para estudantes que tenham cursado integralmente o ensino médio em escolas públicas". 
ao ensino superior e os sistemas de ensino aderem ao processo, em maior ou menor intensidade, como veremos nos quatro estados estudados.

Esse aparato de avaliação criado no Ministério da Educação (MEC) vai se consolidando e, pouco a pouco, envolvendo maiores recursos financeiros, humanos e técnicos. Aspectos relacionados à publicização de resultados mostram cada vez mais o impacto que esses tipos de avaliação produzem na sociedade, revelando também as precárias condições da qualidade do ensino público brasileiro.

Seguindo a mesma lógica do Saeb, os estados criam seus sistemas de avaliação, ora inspirando-se no sistema criado pelo governo federal, ora buscando caminhos próprios, mas, de algum modo, relacionados com as iniciativas desenvolvidas no âmbito da União.

\subsubsection{O Îndice de Desenvolvimento da Educação Básica (Ideb)}

Os resultados acumulados pelo Saeb na série histórica 1995-2005 e o baixo impacto que esses dados vinham provocando nas políticas educacionais ao longo do período, assim como sobre os sistemas de ensino, levou o governo a procurar desenvolver um indicador que facilitasse a leitura e interpretação desses resultados e, ao mesmo tempo, estabelecesse metas para o desempenho dos sistemas de ensino. Criou-se, então, em 2007, o Ideb, que combina resultados do Saeb, considerando agora seu caráter censitário, com taxas de rendimento, mais especificamente a taxa de aprovação. Com isso chegou-se a uma fórmula, que embora não seja tão simples, pode ser expressa numa escala de 0 a 10, facilitando a todos a leitura das informações apresentadas. Além da indicação da situação atual (em 2005), o governo, via Ideb, se preocupou em estabelecer metas bianuais até 2021 para o país, estados, municípios, escolas e etapas da educação básica pública.

O Ideb nasceu como condutor de política pela melhoria da qualidade da educação, tanto no âmbito nacional como nos estados, municípios e escolas, fortalecendo e ampliando a concepção de um Estado Avaliador e a criação de mecanismos de accountability.

0 resgate dessa trajetória no tempo permite evidenciar que a avaliação de larga escala se apresenta como uma política de Estado pela sua continuidade, a despeito das mudanças de governo e de prioridades. No âmbito dos estados, o percurso dos sistemas de avaliação é diferenciado, como se verá a seguir. 


\subsection{Políticas estaduais de avaliação de larga escala}

Os estados participantes da pesquisa - Ceará, Pernambuco, São Paulo e Goiás - desenvolveram seus sistemas de avaliação de larga escala em momentos distintos ao longo dos últimos 20 anos. A seguir, procuramos apresentar uma breve síntese de cada um desses sistemas, começando pelo Ceará, que foi o primeiro a criar um sistema dessa natureza em 1992, quase simultâneo ao Saeb, seguido de São Paulo, que cria em 1996, Pernambuco, em 2000 e Goiás, em 2011.

\subsubsection{Sistema Permanente de Avaliação da Educação Básica do Ceará (Spaece)}

O Ceará foi um dos primeiros estados da federação a desenvolver um sistema próprio de avaliação de larga escala, em 1992. O Spaece foi criado com a finalidade de subsidiar a formulação de políticas educacionais voltadas para a melhoria da aprendizagem com base na aferição do desempenho escolar de alunos. Ao longo do tempo, foram realizadas mudanças no exame, visando seu aprimoramento, o que permitiu torná-lo importante instrumento de monitoramento da rede pública escolar no Ceará.

Em 2004, foi criado um sistema de premiação de escolas da rede estadual mediante a instituição de um $14^{0}$ salário para as unidades com melhor desempenho9. Desde 2007 a sistemática de premiação foi ampliada, estimulada e adotada como política para toda a rede, inclusive mediante a vinculação de recursos do Imposto sobre Circulação de Mercadorias (ICMS) ${ }^{10}$.

As características atuais do Spaece tornaram o sistema mais robusto, configurando-se como uma avaliação externa de caráter censitário, estruturada em três vertentes: Avaliação da alfabetização (Spaece-Alfa, aplicado no $2^{\circ}$ ano do ensino fundamental); Avaliação do ensino fundamental $\left(5^{\circ}\right.$ e $9^{\circ}$ anos$^{11}$; Avaliação do ensino médio (1aa $2^{\underline{a}}$ e $3^{\underline{a}}$ séries). 0 Spaece foi

9 As escolas finalistas (1ㅜㄴ $2^{\circ}$ e $3^{\circ}$ lugar, conforme tipo de oferta) foram então premiadas segundo desempenho absoluto e relativo (maior avanço progressivo). Mais informações sobre o sistema de premiação, ver HOLANDA, M. C.; PETTERINI, F. C.; NOGUEIRA, C. A. G. Um prêmio para a educação. In: HOLANDA, M. C. (Org.). Ceará: a prática de uma gestão por resultados. Fortaleza: Ipece, 2006. p. 160-168.

10 A legislação anterior previa que a distribuição dos $25 \%$ da receita do ICMS aos municípios deveria ser feita da seguinte forma: $75 \%$ de acordo com o Valor Adicionado Fiscal (VAF), que representa o quanto a economia daquela cidade gerou em ICMS, e os $25 \%$ restantes com base: no tamanho da população (5\%); nos gastos com educação (12,5\%) e o restante de forma igualitária entre os municípios (7,5\%).

${ }_{11}$ A partir da Lei no $11.274 / 96$, que organiza o ensino fundamental em nove anos, os anos finais passaram a ser $5^{\circ}$ e $9^{\circ}$ ano. 
criado e implementado pelo governo do estado do Ceará, mas que é aplicado também às escolas municipais dos 184 municípios, tanto nos $2^{\circ}$ e $5^{\circ}$ anos do ensino fundamental como no 9ํㅜ ano desta etapa de educação básica, uma vez que o processo de municipalização do ensino fundamental no estado atingiu também as séries finais, chegando a 2014 com 90,2\% das matrículas.

Na atualidade, o Spaece segue os moldes da Prova Brasil, utilizando a mesma matriz de referência e a teoria de resposta ao item para correção das provas, modificando apenas a periodicidade, que é anual. A partir de 2007, o governo do estado modifica a lei que distribui os $25 \%$ do ICMS para os municípios, passando a estabelecer, por meio da Lei no 14.023/2007, novos critérios de rateio, distribuindo os recursos em função dos resultados obtidos nas áreas de educação, saúde e meio ambiente, tendo por objetivo premiar municípios que se destacassem nessas áreas. As modificações na legislação fizeram com que os $25 \%$ passassem a ser distribuídos da seguinte forma: $18 \%$ com base no Índice de Qualidade da Educação (IQE) ${ }^{12}$, calculado em função dos resultados obtidos no $5^{\circ}$ ano do ensino fundamental e na alfabetização no 2 ano; 5\% no Índice de Qualidade da Saúde e 2\% no Índice de Qualidade do Meio Ambiente.

Ao longo do tempo, o Spaece conquistou centralidade na política educacional do Ceará, sendo seus resultados utilizados como critério para formulação de iniciativas desenvolvidas pelo estado. As escolas da rede estadual não apenas participam ativamente de sua aplicação como desenvolvem práticas no sentido de preparar seus alunos para um bom desempenho nos exames que o integram.

\subsubsection{Sistema de Avaliação do Rendimento Escolar do Estado de São Paulo (Saresp)}

O Sistema de Avaliação de Rendimento Escolar do Estado de São Paulo (Saresp) foi criado pela Secretaria da Educação do Estado de São Paulo, em 1996, tendo como objetivo produzir um diagnóstico da situação da educação básica paulista, visando orientar os gestores no monitoramento das políticas voltadas para a melhoria da qualidade educacional.

O Saresp envolve a aplicação de provas elaboradas contendo questões de língua portuguesa, matemática, ciências humanas, ciências da natureza

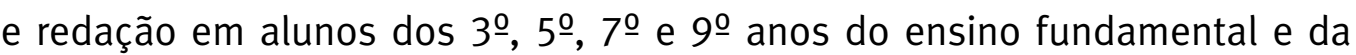

12 O Índice de Qualidade da Educação é calculado anualmente a partir da taxa de aprovação nas cinco primeiras séries do ensino fundamental e do desempenho dos alunos nas avaliações Saeb/Prova Brasil e Spaece no $2^{\circ}$ e $5^{\circ}$ anos do ensino fundamental. Além desses, o índice considera a evolução do aprendizado no ano anterior. 
3 a série do ensino médio. Os resultados são consolidados em boletins, que podem ser consultados pelas escolas estaduais e, também, pelas unidades municipais, técnicas e particulares que aderiram à avaliação.

O estado também criou, em 2007, o Índice de Desenvolvimento da Educação do Estado de São Paulo (Idesp) ${ }^{13}$, calculado a partir de dados do Saresp e do fluxo escolar de cada ciclo e que estabelece metas anuais e individuais que as escolas devem alcançar ano a ano, para cada etapa da escolarização. Esse índice permite também o cálculo do bônus por desempenho pago aos servidores da Educação a cada ano ${ }^{14}$. Instituído pela Lei Complementar no 1.078/2008, o sistema de bonificação por resultados considera o percentual atingido da meta conforme a evolução anual do Idesp de cada escola paulista.

Os resultados do Saresp e do Idesp são divulgados anualmente em boletins específicos para cada escola, disponíveis na internet. Nas palavras de Tavares (2014, p. 159), "a combinação e divulgação de resultados, metas e incentivos torna o sistema de avaliação de São Paulo o primeiro sistema de hard accountability do Brasil”.

\subsubsection{Sistema de Avaliação da Educação Básica de Pernambuco (Saepe)}

A origem do Saepe remonta ao ano 2000, com nova aplicação em 2005 e resultados consolidados e divulgados em 2007. No entanto, se estabelece de forma contínua a partir de 2008, quando passa a se realizar anualmente. Desde 2005, o Saepe adota, na elaboração das provas, a mesma escala do Saeb e a teoria de resposta ao item, o que permite que se estabeleçam comparações entre séries históricas e unidades territoriais.

Os principais objetivos do Saepe são:

- Produzir informações sobre o grau de domínio dos estudantes nas habilidades e competências consideradas essenciais em cada período de escolaridade avaliado. Estes são pré-requisitos indispensáveis não apenas para a continuidade dos estudos, mas para a vida em sociedade.

- Monitorar o desempenho dos estudantes ao longo do tempo, como

Segundo Abreu (2014), “a diferença entre o Índice de Desenvolvimento da Educação Básica (Ideb) do governo federal e o Idesp é que o Ideb considera a nota média dos alunos da escola, enquanto o Idesp é calculado com base na distribuição proporcional dos estudantes em quatro níveis de proficiência: abaixo do básico, básico, adequado e avançado. Portanto, o primeiro mensura a qualidade, e o segundo também a equidade do sistema de ensino" (ABREU, 2014, p. 349).

14 〈http://www.educacao.sp.gov.br/saresp〉. 
forma de avaliar continuamente o projeto pedagógico de cada escola, possibilitando a implementação de medidas corretivas, quando necessário.

- Contribuir diretamente para a adaptação das práticas de ensino às necessidades dos alunos, diagnosticadas por meio dos instrumentos de avaliação.

- Associar os resultados da avaliação às políticas de incentivo com a intenção de reduzir as desigualdades e elevar o grau de eficácia da escola.

- Compor, em conjunto com as taxas de aprovação verificadas pelo Censo Escolar, o Índice de Desenvolvimento da Educação Básica de Pernambuco (Idepe) ${ }^{15}$.

O estado também criou o Índice de Desenvolvimento da Educação de Pernambuco (Idepe), que acompanha os procedimentos estabelecidos na criação do Ideb e que se caracteriza como um índice que permite medir anualmente a qualidade da educação do estado. Sua construção considera os resultados da avaliação do Saepe em língua portuguesa e matemática, dos alunos das $4^{\underline{a}}$ e $8^{\underline{a}}$ séries do ensino fundamental e do $3^{0}$ ano do ensino médio, como também a média de aprovação dos alunos.

Esse índice é requisito para o estabelecimento do bônus de desempenho educacional (BDE), cujas metas estão descritas no Termo de Compromisso que a escola firma com a Secretaria de Educação. O BDE é uma premiação por resultados e foi criado em 2008 para as escolas e em 2009 para as Gerências Regionais de Educação ${ }^{16}$.

O trabalho baseado em metas e em resultados faz parte do Programa de Modernização da Gestão Pública adotado pelo governo de Pernambuco. Na educação, o objetivo é melhorar os indicadores educacionais do estado, sobretudo o Idepe, que impulsionará a elevação do Ideb em virtude da similaridade na metodologia adotada.

De acordo com o setor de Avaliação e Monitoramento das Políticas Educacionais, a avaliação estadual é mais interessante que a nacional, pois, além de ser censitária, permite uma apropriação maior, que serve para

${ }_{15}$ < h t t p:// w w w.siepe.educacao.pe.gov.br/Web Module S me/ itemMenuPaginaConteudoUsuarioAction.do?actionType $=$ mostrar\&idPaginaltemMenuC onteudo $=5912$.

${ }_{16}$ <h t t p:// w w w.siepe.educacao.pe.gov.br/WebModule Sme / itemMenuPaginaConteudoUsuarioAction.do?actionType $=$ mostrar\&idPaginaltemMenuC onteudo=5911 . 
subsidiar a implantação e reformulação das políticas educacionais do estado, traçando metas, objetivos e norteando as atividades das gerências regionais e da própria Secretaria.

Sistema de Avaliação Educacional do Estado de Goiás (Saego)

O Saego foi criado em 2011 com o objetivo de fomentar mudanças na educação oferecida pelo estado, vislumbrando a oferta de um ensino de qualidade. É aplicado de forma censitária para alunos da rede estadual de ensino (e escolas conveniadas participantes) do $2^{\circ}$ ano do ensino fundamental em língua

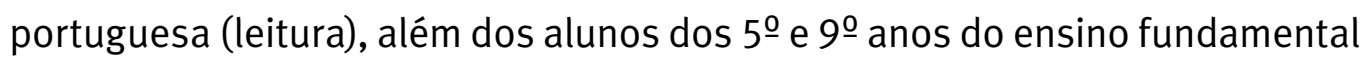
e 3 a série do ensino médio nas disciplinas de língua portuguesa e matemática, nos anos pares. O Saego possui a mesma escala de proficiência do Saeb e tem como base a teoria de resposta ao item, que permite a comparação com anos anteriores, entre escolas e entre turmas, além da análise das respostas certas e erradas, entre outras possibilidades.

Com a aplicação do Saego, foi também criado o Índice de Desenvolvimento da Educação Goiana (Idego), que possibilita ao estado definir metas para as escolas estaduais com base no índice alcançado em 2011.

As considerações sobre os sistemas de avaliação adotados pelos estados focalizados pela pesquisa confirmam a tendência de crescente ampliação de sistemas de avaliação de larga escala no Brasil desde a criação do Saeb, em 1990. Os estados se espelham no modelo nacional para criar seus próprios sistemas, sendo que 19 das 27 unidades federadas (26 estados + Distrito Federal) já o fizeram (MACHADO; ALAVARSE; ARCAS, 2015). Do mesmo modo, avançam no sentido de criar indicadores que permitam a construção de "índices de qualidade da educação" associados a inciativas de impacto sobre a carreira docente, remuneração (incluindo gratificações e prêmios) e até mesmo certificação.

Na visão de Bonamino e Sousa (2012), a institucionalização dessas políticas de bonificação produz reflexos nem sempre benéficos na escola, pois

[...] evidências nacionais e internacionais mostram que principalmente o uso de resultados
das avaliações de terceira geração para informar iniciativas de responsabilização forte pode
envolver riscos para o currículo escolar. Um deles é a situação conhecida como ensinar para
o teste, que ocorre quando os professores concentram seus esforços preferencialmente nos
tópicos que são avaliados e desconsideram aspectos importantes do currículo, inclusive de caráter não cognitivo (BONAMINO; SOUSA, 2012, p. 383).

Estudos de Bauer, Gatti e Tavares (2013) sobre as políticas de premiações 
nos sistemas de avaliação brasileiros mostram que a preparação para os testes é uma alternativa utilizada para se obter ou até mesmo ultrapassar as metas estabelecidas. Se por um lado tais medidas podem representar ganho imediato, por outro, os resultados de médio e longo prazo tendem a se estagnar, uma vez que o objetivo essencial da avaliação, que é a melhoria da aprendizagem discente, passa à margem de iniciativas dessa natureza. Em muitas situações, com vistas a resultados imediatos, são adotadas estratégias meramente instrucionais, comprometendo o desenvolvimento cognitivo e apelando para recursos de treinamento comportamental, precarizando o processo de ensino-aprendizagem.

Em outras situações, como constataram Vidal e Vieira (2015), as avaliações em larga escala atingem a gestão escolar levando-a, em nome da política de premiação, a um retorno de práticas tecnocráticas, que se associam a padrões de conduta que se distanciam do princípio da gestão democrática, impondo uma cultura de gestão por resultados.

De fato, nos quatro estados estudados, o sistema de avaliação de larga escala está associado a um índice que repercute na gestão escolar e na política de avaliação docente, como podemos observar no Quadro 1.

Quadro 1 - Sistemas de avaliação e políticas de premiação/bonificação por estado, 2016

\begin{tabular}{|c|c|c|c|c|}
\hline Estado & $\begin{array}{l}\text { Sistema de } \\
\text { avaliação }\end{array}$ & $\begin{array}{l}\text { Ano de } \\
\text { criação }\end{array}$ & $\begin{array}{c}\text { Política de premiação/ } \\
\text { bonificação }\end{array}$ & $\begin{array}{l}\text { Ano de } \\
\text { criação }\end{array}$ \\
\hline Ceará & Spaece & 1992 & $\begin{array}{l}\text { Prêmio Escola Destaque, } \\
\text { bonificação para equipe } \\
\text { escolar } \\
\text { Prêmio Aprender pra Valer, } \\
\text { bonificação para equipe } \\
\text { escolar e escolas }\end{array}$ & 2004 \\
\hline São Paulo & Saresp & 1996 & $\begin{array}{l}\text { Sistema de Promoção para } \\
\text { os Integrantes do Quadro do } \\
\text { Magistério - Lei Complementar } \\
1.097 / 2009\end{array}$ & 2009 \\
\hline
\end{tabular}




\begin{tabular}{|c|c|c|l|c|}
\hline Pernambuco & Saepe & 2000 & $\begin{array}{l}\text { Bonificação docente } \\
\text { estruturada a partir da Lei de } \\
\text { Responsabilidade Educacional } \\
\text { e dos resultados do Saepe e } \\
\text { Idepe }\end{array}$ & 2008 \\
\hline Goiás & Saego & 2011 & $\begin{array}{l}\text { Bonificação docente: } \\
\text { Programa Reconhecer - } \\
\text { Estímulo à Regência }\end{array}$ & 2011 \\
\hline
\end{tabular}

Fonte: Elaborado pelas autoras com base em Machado, Alavarse e Arcas (2015).

\section{ENTRELACES ENTRE POLÍTICAS NACIONAIS E ESTADUAIS}

As iniciativas nacionais de avaliação de larga escala vêm se constituindo como elemento estratégico das políticas desenvolvidas pelo governo federal na busca de melhoria da qualidade dos sistemas de ensino. Embora remontem aos anos 1990, elas só adquirem maior centralidade na política educacional a partir de 2007, quando da criação do Ideb. A seguir, procuramos analisar os indicadores do Ideb desagregados, para os quatro estados, nas suas respectivas redes públicas, tendo como referência as médias brasileiras nas mesmas redes.

O Gráfico 1 apresenta dados relativos ao indicador de rendimento (aprovação) para o país e os quatro estados no período 2005- 2013, no ensino médio. Nele é possível observar que em dez anos o Brasil apresenta um crescimento da taxa de aprovação de 8,0\%, o Ceará, 13,6\%, Pernambuco, 18,8\%, São Paulo, 3,9\% e Goiás, 18,5\%. Chama a atenção, no entanto, que em 2013, 19\% dos alunos matriculados nesta etapa da educação básica abandonaram a escola ou foram reprovados no ano escolar que estavam cursando, revelando, assim, que cerca de $1 / 5$ dos alunos de ensino médio tem sua trajetória escolar comprometida, quando não descontinuada por eventos produzidos no interior das escolas. 
Gráfico 1 - Saeb/Prova Brasil - Indicador de Rendimento rede estadual

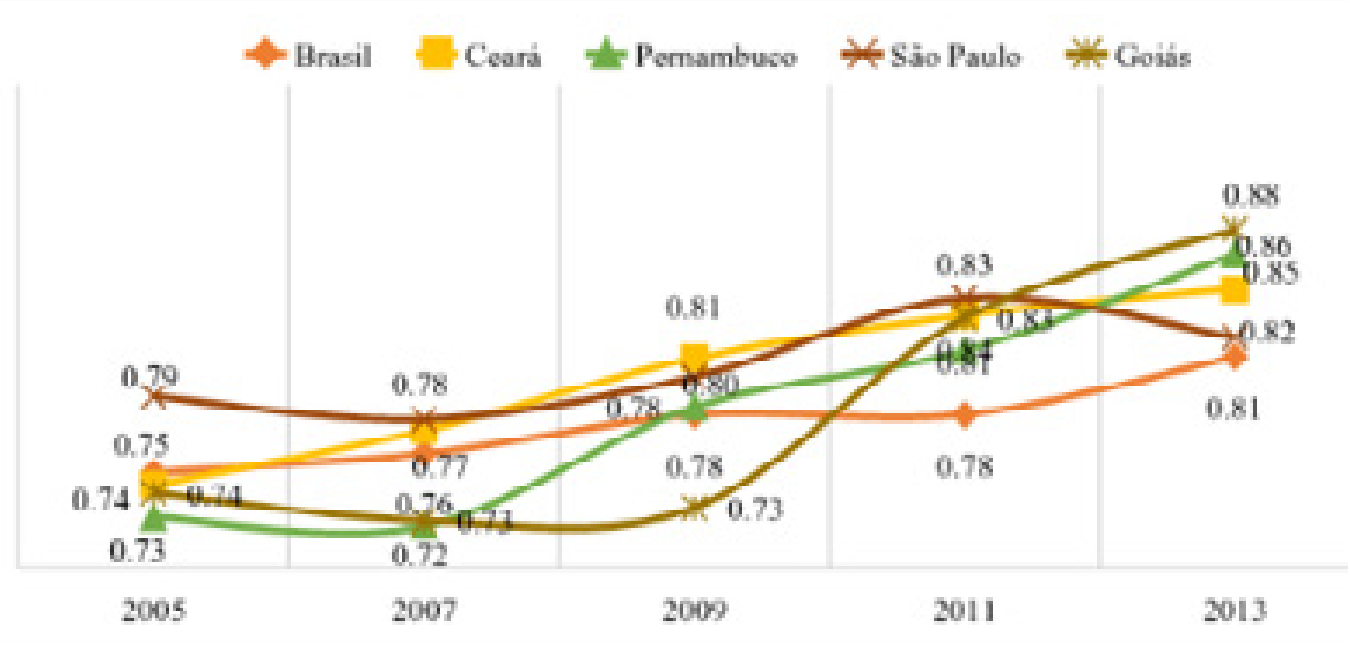

Fonte: Inep/MEC.

Também foram observados os desempenhos dos alunos nas provas de língua portuguesa e matemática no mesmo período. No caso de língua portuguesa, o Gráfico 2 mostra que a média do Brasil cresceu 2,5\%, enquanto o Ceará registra um crescimento de 0,2\%, Pernambuco, 6,5\%, São Paulo, 6,2\% e Goiás, 7,5\%. Considerando que o nível de desempenho na escala do Saeb esperado para esta disciplina é de, no mínimo, 350 pontos ${ }^{17}$, o país e os estados estariam em média $25 \%$ abaixo do valor desejado.

Gráfico 2 - Prova Brasil/Saeb - Língua Portuguesa $3^{0}$ ano do ensino médio, rede estadual

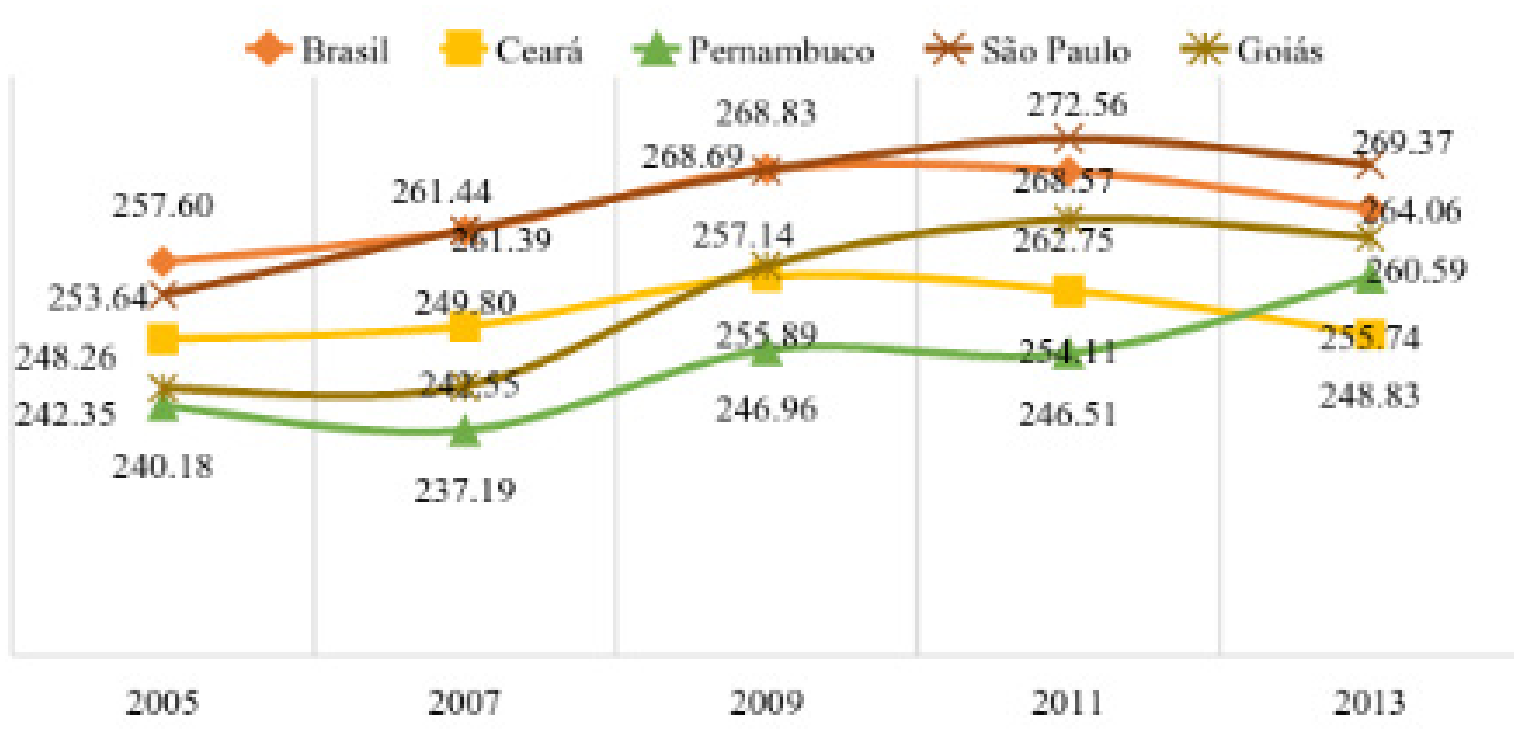

Fonte: Inep/MEC.

${ }_{17}$ Fonte: MEC/Inep. Saeb 2001. Relatório Língua Portuguesa. Ministério da Educação. Brasília, 2002b.

cadernoscenpec | São Paulo | v.6 | n.2 | p.216-245 | jul./dez. 2016 
Em matemática, os resultados apresentados no Gráfico 3 mostram que, em relação ao nível de desempenho esperado na escala de proficiência do Saeb (mínimo de 375 pontos) ${ }^{18}$, estes encontram-se ainda mais distantes, da ordem de $30 \%$. No período 2005-2013, houve um decréscimo na média do país de 0,4\%, e na do Ceará de 0,6\%. Pernambuco, São Paulo e Goiás apresentam crescimento de $6,8 \%, 3,0 \%$ e $5,4 \%$, respectivamente.

Gráfico 3 - Prova Brasil/Saeb - Matemática no $3^{0}$ ano do ensino médio, rede estadual

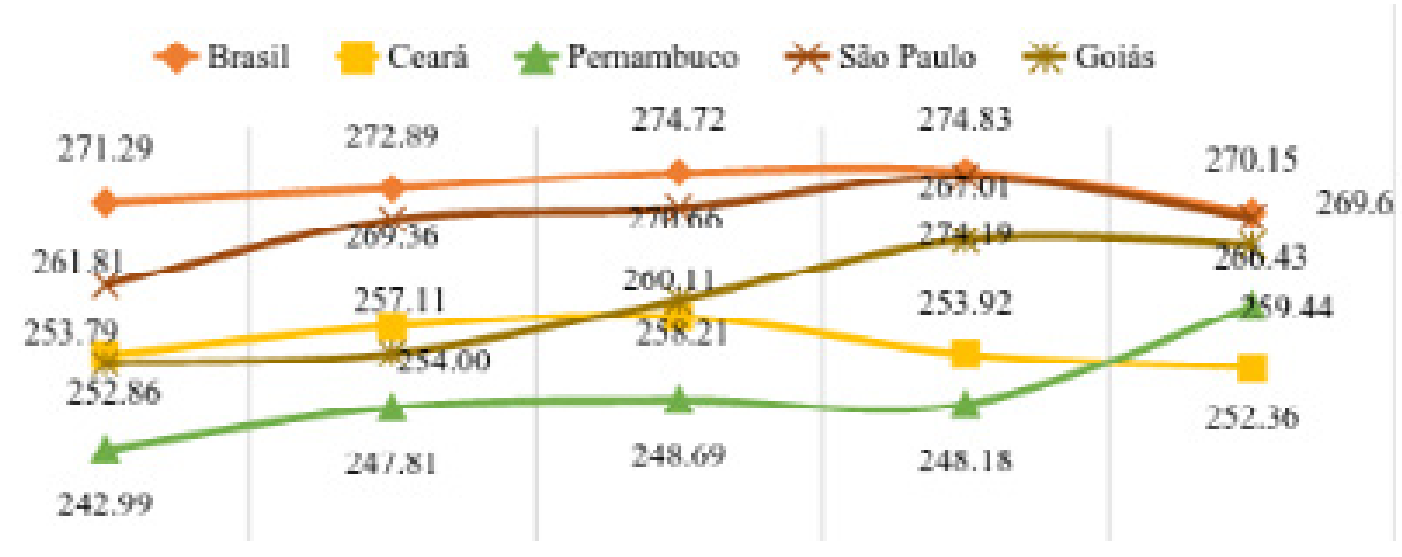

Fonte: Inep/MEC.

Os dados apresentados revelam que os pequenos avanços nos resultados do ensino médio, obtidos pelo país e pelos estados analisados, se deveram, em grande parte, à melhoria decorrente do indicador de rendimento, expresso na taxa de aprovação, estando os resultados de desempenho dos alunos, em vários estados, em situação de estagnação ${ }^{19}$.

Dados do Ideb no período 2005-2013 mostram que o Brasil e alguns estados não vêm atingindo as metas estabelecidas a partir da linha de base de 2005 , como podemos constatar no Gráfico 4.

18 Fonte: MEC/Inep. Saeb 2001. Relatório Matemática. Ministério da Educação. Brasília, 2002a.

19 Quando desagregamos os dados do Ideb, constatamos que 71,5\% do crescimento da média brasileira se deve ao aumento do indicador de rendimento, 26,5\% ao aumento da nota de língua portuguesa e $2 \%$ devido à nota de matemática. 


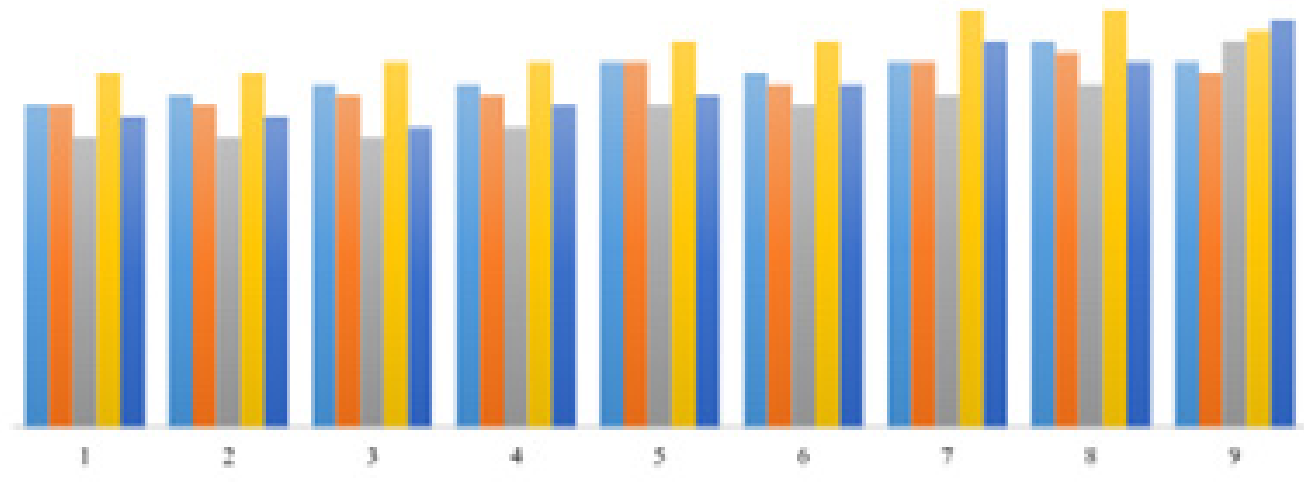

Fonte: MEC/Inep, 2015.

As consequências das políticas de accountability que vêm sendo implementadas pelos estados, fazendo uso das informações obtidas por meio de suas avaliações estaduais de larga escala, têm atingido diretamente os docentes e a gestão escolar no cotidiano escolar, afetando sobremaneira o processo de ensino-aprendizagem. A ideia de associar o desempenho dos alunos à performance de gestores e professores, incluindo nesse modelo sistemática de premiação/bônus, é assunto polêmico entre os profissionais de educação, indo da posição de adesão incondicional ao outro extremo, de rejeição e críticas contundentes a esse modelo de gestão por/para resultados, como veremos em tópico específico.

A discussão sobre o Enem adquire configuração diferenciada em cada estado, como veremos a seguir. Moldado nos termos de uma avaliação de larga escala, o exame possui sua matriz de referência baseada em competências e habilidades, associadas a objetos de conhecimento referenciados nos Parâmetros Curriculares Nacionais (PCN, 1999). Embora a configuração da prova tenha mudado ao longo do tempo, continua envolvendo todas as áreas de conhecimento e trabalhando com itens que favoreçam a interdisciplinaridade e contextualização, conforme preconizam os PCN do Ensino Médio e, mais recentemente, as Diretrizes Curriculares Nacionais para o Ensino Médio (Resolução no 2/2012). Nesse sentido, as provas do Enem abrangem uma gama maior de conteúdo do que as provas aplicadas pelo Saeb e pelas avaliações de larga escala estaduais.

Com a criação do $\operatorname{Sisu}^{20}$ e a lei de cotas, as secretarias de Educação dos

${ }^{20}$ O Sistema de Seleção Unificada (Sisu) é o sistema informatizado gerenciado pelo Ministério da Educação (MEC) no qual instituições públicas de ensino superior oferecem vagas para candidatos participantes do Exame Nacional de Ensino Médio (Enem). 
estados vislumbraram uma oportunidade maior de promover o acesso de jovens que frequentam as redes públicas ao ensino superior público. Assim, em cada estado vamos observar iniciativas diferenciadas de adesão ao Enem por parte das escolas públicas num exemplo claro de como uma política pública concebida no âmbito central é processada, assimilada e encenada pelos atores locais (BALL; MAGUIRE; BRAUNI, 2012).

O Quadro 2 mostra a participação da rede pública estadual no Enem 2014 nos quatro estados selecionados.

Quadro 2 - Participação de escolas e alunos da rede pública estadual, Enem 2014

\begin{tabular}{|c|c|c|c|c|c|c|c|}
\hline & $\begin{array}{c}\text { Escolas } \\
\text { ensino } \\
\text { médio }\end{array}$ & $\begin{array}{c}\text { Escolas } \\
\text { participantes } \\
\text { Enem }\end{array}$ & $\begin{array}{c}\% \\
\text { participação } \\
\text { escolas }\end{array}$ & $\begin{array}{c}\text { Total } \\
\text { alunos } \\
\text { ensino } \\
\text { médio }\end{array}$ & $\begin{array}{c}\text { Matrícula } \\
\text { 30 ano } \\
\text { ensino } \\
\text { médio }\end{array}$ & $\begin{array}{c}\text { Alunos } \\
\text { participantes } \\
\text { Enem }\end{array}$ & $\begin{array}{c}\% \\
\text { participação } \\
\text { alunos }\end{array}$ \\
\hline Ceará & 621 & 583 & $93,9 \%$ & 340.766 & 99.986 & 96.113 & $28,2 \%$ \\
\hline Pernambuco & 801 & 344 & $42,9 \%$ & 332.017 & 100.288 & 39.643 & $11,9 \%$ \\
\hline São Paulo & 3.984 & 1.340 & $33,6 \%$ & 1.617 .899 & 519.610 & 159.155 & $9,8 \%$ \\
\hline Goiás & 614 & 361 & $58,8 \%$ & 219.928 & 71.449 & 40.393 & $18,4 \%$ \\
\hline
\end{tabular}

Fonte: Inep/Sinopse Estatística da Educação Básica, 2014 e Enem 2014. ${ }^{21}$

Dos quatro estados, o Ceará foi o que mais fortemente aderiu ao Enem, chegando em 2014 a contar com 93,9\% das escolas públicas estaduais participando e $28,2 \%$ dos alunos matriculados na rede estadual, o que significa a quase totalidade dos alunos matriculados no 3 ano do ensino médio. Goiás foi o segundo estado que teve maior percentual de escolas da rede pública estadual participando do Enem 2014, e 18,3\% dos alunos matriculados no ensino médio, que corresponde a mais de $50 \%$ dos alunos cursando o 30 ano; Pernambuco, com $42,9 \%$ das escolas públicas estaduais e $11,9 \%$ dos alunos do ensino médio, e São Paulo, com 33,6\% das escolas e apenas 9,8\% dos alunos, se colocam nos últimos lugares em termos de adesão ao exame.

A adesão à política do Enem tem surtido efeitos variados nas escolas públicas, com destaque para a implementação do currículo do ensino médio no cotidiano escolar, assim como nas expectativas dos jovens, que passaram a direcioná-las de forma mais explícita para o ingresso no ensino superior.

21 Estes valores incluem os alunos egressos do ensino médio de todos os estados e que se submeteram ao Enem em 2014. 
Em alguns estados, o Enem vem ocupando um espaço estratégico na dinâmica escolar que se sobrepõe ao Saeb e até mesmo à avaliação estadual no ensino médio. Esse fato ocorre em virtude de ele ser um exame que pode ser aproveitado para múltiplas funções: para o aluno, permite que dispute uma vaga no ensino superior, funcionando como um concurso; para a escola, seus resultados informam o desempenho de todas as áreas de conhecimento, o que significa compartilhar responsabilidades com os professores de todas as disciplinas, não sobrecarregando os docentes de língua portuguesa e matemática, como o Saeb e a maioria dos exames estaduais faz; para os gestores do sistema, funciona como uma ferramenta de gestão, e graças à sua rápida divulgação, permite avaliar resultados e tomar decisões sobre a implementação de medidas de ajuste. Em depoimento, o secretário de Educação do Ceará se posiciona de forma contundente sobre a importância estratégica do Enem para o sistema público ao afirmar que "Para mim, o que é muito claro é o seguinte: o resultado que melhor sintetiza o trabalho do ensino médio é o Enem, nós apostamos nossas fichas no Enem". Tal aposta está evidente na participação quase total de estudantes cearenses do 3 ano do ensino médio neste exame. Resta saber se, proporcionalmente, há mais jovens egressos da escola pública desse estado na educação superior que nos outros estados integrantes da amostra.

\section{ReperCussões no AMBiENTE ESCOLAR}

A ênfase nas avaliações de larga escala por parte do Estado e os avanços nos formatos caracterizados pelas sucessivas gerações, conforme apontam Bonamino e Sousa (2012), fazem com que o elo da cadeia educacional mais atingido seja a escola.

Não se tem notícia, na literatura sobre o assunto, de escolas ou grupo de escolas que tenham se recusado a participar de alguma dessas avaliações, seja as de âmbito estadual, seja as federais. Se a avaliação é censitária, todas participam compulsoriamente; se é amostral, os estabelecimentos selecionados para compor a amostra não têm a opção de rejeitar a participação.

No que diz respeito ao aluno, só resta uma forma de recusa: faltar nos dias das provas. Mas essa alternativa se torna cada vez mais inviável, uma vez que condicionalidades relacionadas ao seu desempenho no ano letivo são criadas, como: dar pontos adicionais para a avaliação bimestral, contar como atividade individual com atribuição de nota, atribuir pontos extras nas notas das disciplinas objeto da avaliação de larga escala, etc. Nos estados em que 
a participação da escola é critério para estabelecimento de premiação/bônus, proliferam alternativas de mobilização dos alunos, incluindo transporte escolar, lanches, pequenos prêmios, etc.

Por outro lado, a visão de gestores, professores e alunos sobre as avaliações de larga escala em que estão diretamente envolvidos - no caso, Saeb/Prova Brasil, as avaliações aplicadas por seus respectivos estados e o Enem varia de incondicional aceitação e adesão a observações mais críticas, como veremos a seguir.

O depoimento de um professor de Pernambuco chama a atenção para a visão gerencialista e empresarial que as avaliações de larga escala podem imprimir à educação ao atribuir premiação/bônus por resultados de desempenho dos alunos. Segundo ele,

Trabalhar com bônus, quando falamos de uma empresa que está produzindo bens inanimados, é muito bom. "Você produziu 100 cadeiras, agora produza 200". Ótimo, mas estamos falando de seres humanos. Cada um tem uma nuance diferente, cada um tem uma ideia diferente. Então, não concordo com essa ideia que diz que "a nota que ele tirou vai mudar o desempenho do bônus do professor". Eu sou contra. Sem contar que a nossa ideia é formar cidadãos para a sociedade e para a universidade (Pernambuco, professor de escola de município de pequeno porte, grifos das autoras).

Os diretores das escolas de Pernambuco também possuem percepções mais críticas sobre os procedimentos relacionados às avaliações de larga escala, como podemos observar nos depoimentos seguintes, quando destacam a sobrecarga de atividades e cobranças que incidem sobre a escola, a busca desenfreada por resultados em detrimento da "qualidade de educação para todos" e a ideia de controle que subjaz ao monitoramento dos processos.

Existe uma sobrecarga na escola em si. O piso da escola. Porque existem as políticas, mas com essa luta pelos resultados, e nós sabemos que tem várias coisas políticas desenvolvidas aí, se cobra muito e se dá poucas condições de trabalho. Precisa-se de investimento e condições de fato para que a gente gere, não um resultado pelo resultado, mas uma qualidade de educação para todos (Pernambuco, diretor de escola de município de pequeno porte, grifos das autoras).

Infelizmente o ser humano parece que precisa estar sendo avaliado, cobrado. Nem todo mundo sabe lidar com a liberdade completa. Há um certo controle, percebemos esse controle por trás disso. Ninguém é ingênuo para não perceber (Pernambuco, diretor de escola de município de pequeno porte, grifo das autoras).

Quando a gente tem pouco pessoal chega um período que você fica estressado, você tem muito que fazer e, como é gestão, um modelo de gestão com foco e resultado, você tem várias planilhas com tudo que você faz, todos os trabalhos são monitorados, você tem que fazer o acompanhamento (Pernambuco, diretor de escola de município de pequeno porte, grifo das autoras). 
Já um diretor de Goiás, que concorda com as avaliações externas e consideraas importantes instrumentos de medida, chama a atenção sobre as limitações que essas mesmas avaliações vêm impondo ao projeto pedagógico da escola, quando, em nome do foco nos resultados que precisam ser alcançados, é necessário abrir mão de projetos e iniciativas que enriqueceriam o currículo escolar e a formação do aluno. Na sua concepção, reduzir a função social da escola a "formar o aluno só para avaliação" provoca um mal-estar.

Acredito muito e defendo muito as avaliações externas, pois elas trouxeram um suporte muito bom para o profissional da educação: a mensuração. Eu só não defendo essa etapa, que estão colocando no processo e na escola, para formar o aluno só para avaliação. [...] Não concordo também com a busca, muitas vezes desesperada, por aquele índice. Então, muitas vezes causa um mal-estar, porque você fica tão preocupado se o índice vai cair, que essa busca desenfreada para mim é um defeito. Assim, fica tão focado na avaliação que você fica com medo de tirar o foco, propor uma Olimpíada de Matemática que, entre aspas, muitas vezes não valeria nada, porque não vai ser utilizada como parâmetro para a escola, só vai ser para o aluno (Goiás, diretor de escola de município de pequeno porte, grifos das autoras).

No Ceará, a visão dos diretores sobre as avaliações de larga escala e as políticas de responsabilização por elas criadas é positiva, sendo as propostas bem-aceitas e assimiladas, inclusive com rebatimento sobre o currículo escolar, como mostra o depoimento a seguir.

Traçar metas, a partir das avaliações foi que a gente começou a trabalhar com vistas a resultados. Porque até um certo periodo, as escolas trabalhavam assim aleatório, afinal de contas qual é a meta que eu preciso atingir? A partir do momento que se cobrou da escola uma gestão por resultados, aí a gente começou a direcionar mais o trabalho da gente, vendo aquelas ações que tinham mais resultado, aquelas que não traziam resultado, ai de certa forma norteou um pouco o trabalho da gente. [...] Essas avaliações externas de um tempo para cá entraram em pauta. Porque antes os professores não tinham nem noção de que existiam descritores, os próprios objetivos de cada avaliação dessa. Hoje eles já estão trabalhando mais de olho nessas avaliações. Até porque a gente faz questão de orientar para que o currículo esteja em sintonia com as diretrizes. E aí, especialmente no caso da Prova Brasil, o próprio aluno a gente faz questão de incentivar (Ceará, diretor de escola de município de grande porte, grifos das autoras).

A sistemática de premiação das escolas por meio dos resultados alcançados tem levado diretores a pressionar professores e alunos, como deixa entender o depoimento do diretor:

A premiação da escola eu acho que é um incentivo muito bom porque o professor ele se sente mais estimulado a produzir e uma das coisas que eu falo e eu faço uma chantagenzinha: "Gente nós temos que inscrever 100\% dos alunos no Enem”. Está ali nossas placas. Toda a vida a gente se inscreve 100\% no Enem. "Nós temos que inscrever 100\% no Enem e os nossos alunos têm que fazer porque senão a gente não ganha premiação nenhuma no final do ano (Ceará, diretor de escola de município de grande porte, grifos das autoras). 


\section{Em São Paulo, a visão dos diretores sobre a avaliação de larga escala está mais atrelada a uma abordagem pedagógica, com ampla discussão dos resultados por parte da gestão escolar, professores e alunos, levando a reflexões sobre as práticas pedagógicas e formação dos professores, como podemos observar nos depoimentos a seguir.}

Os resultados das avaliações são muito discutidos, não é feita avaliação pela avaliação. Já temos uma cultura muito saudável de avaliação aqui, coisa que eu só vi em escolas particulares como Bandeirantes e Etapa, onde eu já trabalhei. Os alunos discutem sobre a avaliação, sobre

os erros, acertos, etc. (São Paulo, diretor de escola de município de grande porte, grifo das autoras).

As avaliações externas e os resultados individualizados também permitem uma devolutiva pedagógica dos resultados para professores e alunos. As professoras coordenadoras também fazem um trabalho de acompanhamento e observação das aulas, orientação e formação dos

professores. Essa dedicação é possível graças ao trabalho da Professora Mediadora, que concentra o atendimento das demandas dos alunos e auxilia muito no trabalho de redução dos índices de evasão (São Paulo, diretor de escola de município de pequeno porte, grifo das

autoras).

Os resultados são utilizados para análise e reflexão sobre as práticas pedagógicas, busca-se conhecer os principais erros e dificuldades, fazer diagnósticos e compreender os desafios e problemas a serem enfrentados (São Paulo, diretor de escola de município de pequeno porte,

grifo das autoras).

\section{0 trabalho colaborativo entre gestão escolar, professores e alunos, na percepção dos dois últimos diretores, é que faz a diferença na luta pelos resultados da escola, como mostram os depoimentos.}

Eu acho que, o bom resultado vem da direção, porque se não fosse essa direção, assim porque muitas escolas deixam a desejar, por isso eu acho que assim quando eu entrei aqui foi essa união da direção, com os professores, com os alunos. Eu acho que isso aí faz crescer mais e mais (Pernambuco, professor de escola de município de médio porte, grifo das autoras).

Os alunos pediram para a gente montar um grupo para ajudá-los no Enem [...] então assim, aqueles que querem aprender mais a gente tenta criar condições para que eles possam aprofundar seus conhecimentos. Aqueles que têm dificuldades, dá o reforço para eles e aqueles que não têm dificuldade, mas querem aprender mais, tem que dar a oportunidade para eles também, um aprendizado a mais para eles (São Paulo, professor de escola de município de grande porte, grifo das autoras).

Eu acho que a questão de a escola ter os resultados que tem é os professores mesmo, o jeito que eles aplicam prova, os professores chegam lá e dizem "minha gente vamos correr atrás das provas de vocês porque aqui ninguém vai baixar o nivel não”. A maneira deles de estarem sempre incentivando a gente a ter um futuro. Muitos jovens têm um problema de não ter ao que se agarrar, não ter um sonho a seguir e aqui não, os professores incentivam, não só os professores, mas a direção do colégio, e em época de Enem a gente se reúne na quadra e tem toda aquela motivação para a gente ter um curso superior (Ceará, diretor de escola de município de médio porte, grifos das autoras). 
Embora os depoimentos obtidos durante a pesquisa nos quatro estados selecionados não representem uma visão abrangente sobre essas questões, oferecem pistas de como as avaliações de larga escala estão chegando às escolas, que estratégias e mecanismos de enfrentamento e sobrevivência são concebidos e implementados. Não se percebeu, em nenhum momento, a mais remota intenção de recusa em participar de processos dessa natureza, sendo essas avaliações dadas como fatos consumados, cabendo às escolas, exclusivamente, o desafio de "suprir", num esforço quase sobre-humano, as dificuldades de toda ordem que os estudantes acumulam ao longo de sua trajetória de vida, marcada, vida de regra, pela privação de oportunidades.

\section{Problemas, desafios e PERSPECTIVAS}

As considerações apresentadas neste artigo oferecem uma contribuição para posterior reflexão e aprofundamento. De uma maneira geral, permitiram perceber o crescente protagonismo da avaliação como política dominante nos sistemas de ensino. Tal tendência, advinda de um cenário propício à elaboração de agendas internacionais, é facilitada pela presença de robustos sistemas de estatísticas internacionais, nacionais e subnacionais, como é o caso dos quatro estados aqui considerados.

Iniciados de forma relativamente modesta no começo dos anos 1990 e fortalecidos com o passar dos anos, tanto os sistemas nacionais - caso do Saeb e do Enem - quanto os estaduais aqui considerados - Spaece, Saresp, Saepe e Saego - hoje possuem inegável protagonismo na formulação e implementação de políticas públicas, todos com forte impacto sobre as redes de ensino. Se é verdade que a presença de robustos sistemas de avaliação provocou uma cultura de avaliação de resultados, não deixa de surpreender como a melhoria do desempenho de estudantes brasileiros tem sido lenta e, em alguns casos, encontre-se praticamente estagnada.

A análise da configuração dos sistemas nacionais e estaduais projeta luz sobre a existência de muito mais semelhanças que diferenças entre uns e outros. Se assim é, caberia indagar: não estaria havendo uma indesejável duplicação de esforços e recursos em nome da melhoria da qualidade da educação brasileira e dos estados em questão? Os extratos de depoimentos dos profissionais da escola entrevistados no decorrer da pesquisa evidenciam não apenas uma aguda consciência de que a cultura de avaliação chegou para ficar, bem como alguns efeitos deletérios gerados pelos excessos delas decorrentes sobre os processos de ensino-aprendizagem. 
Por outro lado, é inegável que algo de bom as avaliações trouxeram para o cotidiano escolar, cuja expressão mais evidente é a presença de um contingente muito mais representativo de jovens egressos da escola na educação superior, aí incluindo as universidades públicas, até pouco tempo território exclusivo dos filhos das elites econômicas. A diretividade dos processos de preparação dos alunos para a melhoria do desempenho escolar, associada à criação do Sisu, que tem como critério seletivo os resultados do Enem juntamente com a lei de cotas, começa a transformar as feições das universidades públicas brasileiras. 


\section{Contexts, policies and results of secondary education assessment: a study in four brazilian states}

Abstract: This study discusses national and state large-scale assessment policies in four Brazilian states - São Paulo, Goiás, Pernambuco and Ceará - focusing on the effects of these policies on secondary schools with good performance levels situated in high socio-spatial vulnerability areas. The sample comprised 24 schools and the methodology involved quantitative and qualitative analyses. By analyzing the configurations of the national and state systems, we found that there are more similarities than differences between them, which led us to question whether equivalent efforts and resources are not being employed twice to improve the quality of education, thus burdening schools and everyone involved. Participants' accounts show an acute awareness that the assessment culture is here to stay, and stress some harmful effects of its excesses.

Keywords: Educational policy. Large-scale assessment. Secondary education. School management. 


\section{Contextos, políticas y resultados de evaluación en la enseñanza media: un estudio en cuatro estados brasileños}

Resumen: Este estudio discute las políticas de evaluación a gran escala, a nivel federal y estatal (provincial), en cuatro estados de Brasil -São Paulo, Goiás, Pernambuco y Ceará-, centrándose en su repercusión en escuelas de enseñanza media con buenos resultados, ubicadas en territorios socioespaciales vulnerables. El muestreo incluyó 24 escuelas y la metodología adoptada se basó en el análisis cuanticualitativo. El estudio de la configuración de los sistemas nacionales y estatales muestra la existencia de más semejanzas que diferencias entre unos y otros, lo que llevaría a indagar si no estaría habiendo una duplicación de esfuerzos y recursos en pro de la mejora de la calidad de la educación, generando una sobrecarga a las escuelas y a todos los involucrados. Los testimonios de los participantes evidencian una aguda conciencia de que la cultura de evaluación ha llegado para quedarse, y llama la atención hacia algunos efectos perjudiciales generados por sus excesos.

Palabras clave: Política educacional. Evaluación a gran escala. Enseñanza media. Gestión escolar. 


\section{REFERÊNCIAS}

ABREU, Mariza. Diretrizes nacionais e carreira docente em São Paulo. In: NEGRI, Barjas; TORRES, Haroldo da Gama; CASTRO, Maria Helena Guimarães de. (orgs). Educação básica no Estado de São Paulo: avanços e desafios. São Paulo: Seade/FDE, 2014. p. 327 - 358.

AFONSO, Almerindo Janela. Reforma do Estado e políticas educacionais: entre a crise do Estado-nação e a emergência da regulação supra-nacional. Educação \& Sociedade, Campinas, v. 22, n. 75, p. 15-29, ago. 2001.

BALL, S.; MAGUIRE, M.; BRAUN, A. How schools do policy: policy enactments in secondary schools. London: Routledge, 2012.

BARROSO, João. O Estado, a educação e a regulação das políticas públicas. Educação \& Sociedade, Campinas, v. 26, n. 92, p. 725-751, Especial - out. 2005.

BAUER, Adriana; GATTI, Bernardete A.; TAVARES, Marialva (Org.). Vinte e cinco anos de avaliação de sistemas educacionais no Brasil: Origem e pressupostos. São Paulo: Insular Livros/Fundação Carlos Chagas, 2013. (v. 1).

BONAMINO, Alicia; SOUSA, Sandra Zákia. Três gerações de avaliação da educação básica no Brasil: interfaces com o currículo da/na escola. Educação e Pesquisa, São Paulo, v. 38, n. 2, p. 1-16, fev. 2012.

BRASIL. Lei no 9.394, de 20 de dezembro de 1996. Estabelece as diretrizes e bases da educação nacional. Disponível em: 〈http://www.planalto.gov.br/ ccivil_03/leis/ 19394.htm>. Acesso em: 28 set. 2014.

BRASIL. Portaria Ministerial no 931, de 21 de março de 2005

FREITAS, Luiz Carlos de (Org.). Avaliação de escolas e universidades. Campinas: Komedi, 2003.

GATTI, Bernadete. Avaliação de sistemas educacionais no Brasil. Sísifo: Revista de Ciências da Educação, n. 9, p. 7-17, maio/ago. 2009.

HOLANDA, M. C.; PETTERINI, F. C.; NOGUEIRA, C. A. G. Um prêmio para a educação. In: HOLANDA, M. C. (org). Ceará: a prática de uma Gestão Pública por Resultados. Fortaleza, IPECE, 2006. p. 160-168. Disponível em: http:// www.ipece.ce.gov.br/ publicacoes/Ceara_GPR.pdf. Acesso em 07/02/ 2016. 
LEVIN, Benjamin. Reforming education: from origins to outcomes. London: Routledge Falmer, 2001.

MACHADO, Cristiane; ALAVARSE, Ocimar Munhoz; ARCAS, Paulo Henrique. Sistemas estaduais de avaliação: interfaces com qualidade e gestão da educação RBPAE, v. 31, n. 3, p. 667-680, set./dez. 2015.

MAINARDES, J. Abordagem do ciclo de políticas: uma contribuição para a análise de políticas educacionais. Educação \& Sociedade, Campinas, v. 27, n. 94, p. 47 - 69, jan./abr. 2006. Disponível em: 〈www.scielo.br/pdf/es/v27n94/ a03v27n94.pdf). Acesso em: 17 nov. 2013.

MAROY, Christian. Em direção a uma regulação pós-burocrática dos sistemas de ensino na Europa? In: OLIVEIRA, Dalila Andrade; DUARTE, Adriana (Org.). Políticas públicas e educação: regulação e conhecimento. Belo Horizonte: Fino Traço, 2011. p. 19-46.

RUA, Maria das Graças. Análise de políticas públicas: conceitos básicos. s. d. Disponível em: 〈http://www.dieese.org.br/dieese/projetos/SUPROF/ Analisepoliticas publicas.PDF. Acesso em: 30 set. 2014.

TAVARES, Priscilla Albuquerque. Ensino fundamental: evolução dos indicadores, qualidade e contexto. In: NEGRI, Barjas; TORRES, Haroldo da Gama; CASTRO, Maria Helena Guimarães de. (orgs). Educação básica no Estado de São Paulo: avanços e desafios. São Paulo: Seade/FDE, 2014. p. 155-168.

TEODORO, A. Os novos modos de regulação transnacional das políticas de educação: a regulação pelos resultados e o papel das comparações internacionais. In: TEODORO, A.; JEZINE, E. (Org.). Organizações internacionais e modos de regulação das políticas de educação: indicadores e comparações internacionais. Brasília: Líber Livro, 2012. p. 17-34.

VIDAL, Eloisa Maia; VIEIRA, Sofia Lerche. Gestão democrática da escola: um modelo e seus desafios. In: Simpósio brasileiro de política e administração da educação, 27., 2015. Olinda, PE. Disponível em: 〈http://www.anpae.org. br/simposio 2015/app/views/gt1-com/SofiaLerche Vieira-GT01-comunicacaores.pdf〉. Acesso em: 30/04/2016.

VIEIRA, Sofia Lerche. Gestão, avaliação e sucesso escolar: recortes da trajetória cearense. Estudos Avançados, v. 21, n. 60, p. 45-60, 2007. Disponivel em: 〈http://www.scielo.br/pdf/ea/v21n60/a04v2160.pdf〉. Acesso em: 13/08/2015. 
WERLE, Flavia Corrêa Obino. Avaliação em larga escala: foco na escola. Brasília: Líber Livro, 2010.

Políticas de avaliação em larga escala na educação básica: do controle de resultados à intervenção nos processos de operacionalização do ensino. Ensaio: Avaliação e Políticas Públicas em Educação, Rio de Janeiro, v. 19, n. 73, p. 769-792, out./dez. 2011.

Sobre as autoras:

Sofia Lerche Vieira é doutora em Filosofia e História pela Pontifícia Universidade de São Paulo (PUC/SP). Atua como professora do Programa de Pós-graduação da Universidade Estadual do Ceará (Uece).

E-mail: sofialerche@gmail.com

Eloísa Maia Vidal é doutora em Educação pela Universidade Federal do Ceará e professora da Uece.

E-mail: eloisamvidal@yahoo.com.br

Willana Nogueira M. Galvão é mestranda em Educação na Universidade Federal de Pernambuco.

E-mail:willananogueira@hotmail.com

Recebido em: abril de 2016

Aprovado em: junho de 2016 